July 2004 Volume $97 \quad$ Number 7 ISSN 0141-0768

\section{Coronary artery bypass grafting on the beating heart: changing the paradigm}

Over the past decade coronary artery bypass grafting (CABG) on the beating heart (off-pump or OPCAB) has become a standard procedure in many centres worldwide; however, the practice of OPCAB ranges from 0\% to $100 \%$ of cases, even between surgeons operating in the same unit. This variation is the result of several interrelated factors, the most important of which is the question of graft patency. Some surgeons express concern about the quality of distal anastomoses performed on a moving field, and question the need to alter their practice from the perceived gold standard of conventional coronary artery surgery with cardiopulmonary bypass and cardioplegic arrest. This scepticism is self perpetuating, since a lack of familiarity reinforces the perception that $\mathrm{OPCAB}$ is technically too demanding or gives worse outcomes. Another major consequence is a paucity of adequate training in OPCAB techniques. In truth, the evidence to date indicates that OPCAB, when compared with conventional CABG, is associated with at least equivalent clinical outcome at lower cost. $^{1-11}$ Furthermore, training in OPCAB techniques, as part of a structured programme, has been shown to be safe and successful. ${ }^{12,13}$ Existing evidence challenges the paradigm that conventional on-pump CABG represents the gold standard in surgical revascularization. This has important implications for the future practice of cardiac surgery. In particular, are current cardiothoracic training programmes in the UK and elsewhere capable of training the next generation of surgeons in OPCAB techniques?

\section{Outcomes after off-pump surgery}

In the randomized clinical trials of off-pump versus onpump surgery, the number of vessels treated has generally been equivalent in the two groups, with short-term outcomes either better or similar for off-pump surgery. In the Beating Heart against Cardioplegic Arrest Studies (BHACAS) we randomized 401 patients to either on or off pump multivessel CABG. ${ }^{1}$ In BHACAS-1 patients were excluded if they required grafts to the distal marginal branches, had poor left ventricular function or had recent myocardial infarction, although these were included in BHACAS-2. A meta-analysis of these studies showed that postoperative inotropic requirements, postoperative blood loss and consequent transfusion requirement, intubation time, frequency of postoperative chest infections and arrhythmias, intensive care unit stay and hospital length of stay were all significantly lower for off-pump CABG. ${ }^{1}$

The Octopus Study Group randomized 281 patients in a multicentre study, ${ }^{2}$ and Puskas and colleagues at Emory University $^{3}$ randomized 200 patients, to either on or off pump multivessel CABG. In both trials, those undergoing off-pump surgery had shorter ventilation times, were discharged from hospital earlier and bled less, requiring fewer transfusions. Results of PRAGUE-4 (400 patients randomized) likewise favoured off-pump surgery, with the exception of number of distal anastomoses performed, which was lower; total hospital costs were about 25\% less for off-pump surgery. ${ }^{4}$ Two other trials, by Légare ${ }^{5}$ (300 randomized) and Gerola ${ }^{6}$ (160) and co-workers, revealed no significant differences in short-term outcomes.

The patients recruited in these randomized trials were usually selected in some way-e.g. for low risk or limited vascular disease. Only in PRAGUE-4 were they specified to be unselected. But registry data, which are more inclusive and therefore more representative of overall practice, likewise point to advantages for off-pump CABG. ${ }^{8,9}$ Cleveland and co-workers, ${ }^{9}$ in a multicentre risk-adjusted analysis of 118140 patients undergoing isolated CABG (11 717 off pump) drawn from the National Adult Cardiac Surgery Database of the Society of Thoracic Surgeons, showed significant benefits associated with off pumplower operative mortality (2.3\% versus $2.9 \%)$ and fewer major complications such as deep sternal wound infection, bleeding, renal failure and need for prolonged ventilation (overall complication rate $10.6 \%$ versus $14.1 \%$ ). Lower morbidity with OPCAB is attributed to avoidance of the haemostatic and systemic inflammatory activation and the gaseous and particulate emboli that result from cardiopulmonary bypass. These benefits are especially pronounced in those at higher risk of cardiopulmonary-bypass-associated morbidity — notably, people of advanced age and those with poor left ventricular function, renal impairment, obesity or diabetes. $^{14}$ In the largest contemporary multicentre comparison (17969 OPCAB patients) of outcomes in multivessel CABG performed with and without cardiopulmonary bypass, subgroup analysis of propensity-matched 
groups identified off-pump survival benefits in patients with previous CABG (odds ratio 0.53), diabetes (0.66), left ventricular ejection fraction $30-50 \%(0.75)$, and age 66-75 years $(0.80)$; also, the odds ratio in women was 0.79 .14

\section{Graft patency}

The success of coronary artery bypass grafting is ultimately measured by long-term graft patency. The difficulties of operating on the beating heart, especially when grafting vessels on the lateral or inferior wall, might compromise the quality of the distal anastomoses and result in inferior long-term graft patency. So, might the improvements in short-term outcome be at the expense of long-term benefits? Large observational studies report excellent angiographic patency following $\mathrm{OPCAB}$, although these are prone to reporting bias. Puskas et al. ${ }^{15}$ assessed 421 grafted arteries in 167 OPCAB patients and reported early graft patency rates of $98.8 \%$. Similarly in an observational study of 257 patients undergoing total arterial grafting, early postoperative angiography revealed 97.8\% (264/270) patency of internal thoracic arteries and 97.9\% (512/523) patency of radial arteries in 238 patients following off-pump surgery. ${ }^{16}$ In contrast, Khan and colleagues, ${ }^{17}$ in a randomized study of 104 CABG patients (angiographic follow-up incomplete), reported graft patency rates at three months of $98 \%$ and $88 \%$ in on and off pump groups, respectively - a highly significant difference $(P<0.002)$. The two surgeons in this trial only occasionally performed off-pump surgery in their normal practice, however $(13 \%$ of all CABG cases in the preceding two years), and it is difficult to see how this cannot have introduced a bias into the result. Analysis of 16988 consecutive patients operated on in seventy-two US centres demonstrated that OPCAB performed in low as opposed to high volume OPCAB units was associated with significantly greater cardiac specific as well as overall mortality. ${ }^{18}$ Angiographic follow-up of a subgroup of patients from the multicentre Octopus Study Group trial, where operators were more familiar with OPCAB techniques, demonstrated one-year patency of $93 \%$ and $91 \%$ for on and off pump, respectively (absolute difference 2\%; 95\% confidence interval -6.5 to $+10.4) .^{10}$

Neither of these randomized trials was powered to detect differences in graft patency, and adequately sized angiographic follow-up of randomized trials of on versus OPCAB have yet to be performed. Clinical follow-up of several large randomized studies does not, however, support the notion that graft patency is inferior following OPCAB. Lower graft patency ultimately results in higher mortality and frequency of cardiac related events, an earlier requirement for repeat revascularization procedures. Midterm follow-up of the BHACAS-1 and BHACAS- 2 patients demonstrated no difference in mortality or cardiac events at a mean follow-up of 25 months for BHACAS- 1 and 14 months for BHACAS-2. $33(17 \%)$ of 200 patients in the off-pump group died or had a cardiac-related event, compared with 42 (21\%) of 201 in the on-pump group (odds ratio $0.78 ; 95 \%$ confidence interval 0.49 to 1.22). Similarly, one-year follow-up from the Octopus trial ${ }^{10}$ revealed no difference in the rate of freedom from death, stroke, myocardial infarction, and coronary reintervention-91\% on-pump versus $88 \%$ offpump (absolute difference 2.6\%; 95\% confidence interval -4.6 to +9.8$)$. This study also revealed no difference in quality of life between the two groups; in both groups EuroQol summary scores increased from 0.65 at baseline to 0.84 three months postoperatively. Analysis of disease specific and generic quality of life in BHACAS-1 and -2 patients at a median of three years' follow-up likewise revealed no difference between on and off pump groups. ${ }^{11}$

\section{Training and OPCAB}

Whilst some practising surgeons remain to be convinced of the merits of OPCAB, this is not the case with the next generation of surgeons. In a survey of cardiothoracic trainees in the UK, 96\% felt that training in OPCAB was essential (S Bays, GD Angelini, unpublished). Scepticism on the part of trainers has had a negative effect on the widespread introduction of OPCAB techniques, however, and only $51 \%$ of UK trainees surveyed had gained experience of $\mathrm{OPCAB}$ in their training programme. Bristol has led the way in training in OPCAB techniques, and over the past five years we have successfully trained four of our residents in off-pump surgery, three of whom are now consultants. As OPCAB surgery was integrated into the training programme at our institution the proportion of OPCAB procedures performed by trainees increased from $18 \%$ to $62 \%$ between the years 1999 and 2001. ${ }^{13}$ The initial phase was aimed at making the trainees familiar with handling the beating heart and learning the technique of exposing and stabilizing the target vessels. Once they had acquired proficiency with this they were allowed to perform anastomoses on the anterior surface of the heart (mostly left internal mammary to left anterior descending or grafting of the diagonal branches) before gradually moving to posterior descending and circumflex grafting. In 2001, we reported our experience of the early and mid-term clinical outcome of OPCAB procedures performed by supervised trainees or senior surgeons. Multivariate analysis demonstrated that the risk of morbidity or mortality was not increased if the OPCAB procedure was performed by a trainee. ${ }^{12}$ 
Thereafter, trainees with experience of at least 50 supervised OPCAB cases were allowed to perform procedures without supervision. In a new analysis, clinical outcomes of OPCAB procedures performed by trainees differed little whether they operated independently or under consultant supervision. ${ }^{13}$ Furthermore the results of OPCAB performed by trainees $(n=422)$ were superior to those they performed on pump $(n=547)$ over the same period. ${ }^{13}$ The Emory University group has similarly demonstrated that the learning curve in $\mathrm{OPCAB}$ can be traversed without any increase in patient morbidity ${ }^{19}$-an achievement they attributed to careful case selection such that high-risk patients with poor left ventricular function, left main stem or complex three-vessel disease were excluded from OPCAB until sufficient operator experience (over 200 cases) had been obtained. Analysis of the Bristol patient registry demonstrates a similar trend. ${ }^{13}$ In a separate analysis of those high-risk OPCAB patients operated on by trainees or consultants there was no significant difference between the groups for morbidity or mortality (the frequency of perioperative myocardial infarction was actually higher in the consultant group) after adjustment for potentially confounding preoperative factors. ${ }^{20} \mathrm{Re}$ cently, continuous performance monitoring has been introduced to complement our training programme by monitoring changes in performance over time and alerting trainers to suboptimal performance. This has shown that cumulative performance (as assessed by variable lifeadjusted displays and risk-adjusted probability ratio tests) by trainees becomes equal to, or better than, that of a consultant after approximately 100 OPCAB cases. In addition, performance for all trainees in off-pump cases was equivalent to or better than their performance with conventional on-pump CABG. ${ }^{21}$ From this evidence we conclude that, where senior surgeons are proficient in OPCAB techniques, a structured cardiothoracic training programme that includes OPCAB surgery is both possible and safe for patients.

\section{Conclusion}

As the clinical evidence in support of OPCAB mounts, a consensus must be reached as to the indications for OPCAB surgery. What is clear from the current evidence is that, in certain patients, OPCAB offers advantages over conventional CABG and that the existing paradigm must change. Cardiothoracic training in the UK is not yet addressing this change.

\section{G J Murphy \\ G D Angelini}

Bristol Heart Institute, University of Bristol, Bristol Royal Infirmary, Bristol BS2 8HW, UK

Correspondence to: Professor G D Angelini

E-mail: G.D.Angelini@bristol.ac.uk

\section{REFERENCES}

1 Angelini GD, Taylor FC, Reeves BC, Ascione R. Early and midterm outcome after off pump and on pump surgery in Beating Heart Against Cardioplegic Arrest Studies (BHACAS 1 and 2): a pooled analysis of two randomised controlled trials. Lancet 2002;359: $1194-9$

2 van Dijk D, Nierich AP, Jansen EW, et al. Octopus Study Group. Early outcome after off pump versus on pump coronary bypass surgery: results from a randomized study. Circulation 2001;104:1761-6

3 Puskas JD, Williams WH, Duke PG, et al. Off pump coronary artery bypass grafting provides complete revascularisation with reduced myocardial injury, transfusion requirements, and length of stay: a prospective randomized comparison of two hundred unselected patients undergoing off pump versus conventional coronary artery bypass grafting. J Thorac Cardiovasc Surg 2002;125: 797-806

4 Straka Z, Widimsky P, Jirasek K, et al. Off-pump versus on-pump coronary surgery: final results from a prospective randomized study Prague-4. Ann Thorac Surg 2004;77:789-9

5 Légaré JF, Buth KJ, King S, et al. Coronary bypass surgery performed off pump does not result in lower in-hospital morbidity than coronary artery bypass grafting performed on pump. Circulation 2004;109: 887-92

6 Gerola LR, Buffolo E, Jisbic W, et al. Off-pump versus on-pump myocardial revascularization in low-risk patients with one or two vessel disease: perioperative results in a multicenter randomized controlled trial. Ann Thorac Surg 2004;77:569-73

7 Ascione R, Lloyd CT, Underwood MJ, Lotto AA, Pitsis AA, Angelin GD. Economic outcome of off pump coronary artery bypass surgery: a prospective randomized study. Ann Thorac Surg 1999;68: 2237-42

8 Magee MJ, Jablonski KA, Stamou SC, et al. Elimination of cardiopulmonary bypass improves early survival for multivessel coronary artery bypass patients. Ann Thorac Surg 2002;73: 1196-203

9 Cleveland JC Jr, Shroyer AL, Chen AY, Peterson E, Grover FL. Off pump coronary artery bypass grafting decreases risk-adjusted mortality and morbidity. Ann Thorac Surg 2001;72:1282-8

10 Nathoe HM, van Dijk D, Jansen EW, et al. A comparison of on pump and off pump coronary bypass surgery in low-risk patients. $N$ Engl J Med 2003;348:394-402

11 Ascione R, Reeves BC, Taylor FC, Seehra HK, Angelini GD. Beating Heart Against Cardioplegic Arrest Studies (BHACAS 1 and 2): quality of life at mid-term follow-up in two randomised trials. Eur Heart J 2004;25:765-70

12 Caputo M, Chamberlain M, Ozalp F, et al. Off-pump coronary operations can be safely taught to cardiothoracic trainees. Ann Thorac Surg 2001;71:1215-19

13 Caputo M, Bryan AJ, Capoun R, et al. The evolution of training in off pump coronary surgery in a single institution. Ann Thorac Surg 2002;74(suppl):S1403-7

14 Magee MJ, Coombs LP, Peterson ED, Mack MJ. Patient selection and current practice strategy for off-pump coronary Artery bypass surgery. Circulation 2003;108(suppl II):119-14

15 Puskas JD, Thourani VH, Marshall JJ, et al. Clinical outcomes, angiographic patency, and resource utilisation in 200 consecutive off-pump coronary bypass patients. Ann Thorac Surg 2001;71: 1477-83

16 Kobayashi J, Tagusari O, Bando K, et al. Total arterial off-pump coronary revascularization with only internal thoracic artery and composite radial artery grafts. Heart Surg Forum 2002;6: 30-7

17 Khan NE, De Souza A, Mister R, et al. A randomized comparison of off pump and on pump multivessel coronary-artery bypass surgery. N Engl J Med 2004;350:21-8 
18 Brown PP, Mack MJ, Simon AW, et al. Comparing clinical outcomes in high-volume and low-volume off-pump coronary bypass operation programs. Ann Thorac Surg 2001;72:\$1009-15

19 Song HK, Petersen RJ, Sharoni E, Guyton RA, Puskas JD. Safe evolution towards routine off-pump coronary artery bypass: negotiating the learning curve. Eur $J$ Cardiothorac Surg 2003;24:947-52
20 Ascione R, Reeves BC, Pano M, Angelini GD. Trainees operating on high-risk patients without cardiopulmonary bypass: a high-risk strategy? Ann Thorac Surg (in press)

21 Caputo M, Reeves BC, Rogers CA, Ascione R, Angelini GD. Monitoring the performance of residents during training in off-pump coronary surgery. J Thorac Cardiovasc Surg (in press)

\section{Direct reporting of suspected adverse drug reactions by patients}

Adverse drug reactions (ADRs) are a serious cause for concern in both adults and children. ${ }^{1}$ Of child inpatients, nearly one in ten experiences an ADR - severe in $12 \% .^{2}$ For adults in hospital, ADRs are thought to be among the six major causes of death: in the USA, according to one estimate, over 100000 hospital patients die each year as a result of such reactions. ${ }^{3}$ Within the UK at least ten suspected fatal ADRs are reported in children each year. ${ }^{4}$

How good are we at detecting harmful effects that escaped notice in the prelicensing phase of a drug? The 'yellow card' system, which depends largely on voluntary reporting by doctors, has long been seen as inadequate; and two leading critics, Charles Medawar and Andrew Herxheimer, have used their experience with patient reports on the antidepressant paroxetine ${ }^{5}$ to argue that patients in the UK should have the right to report ADRs directly. This campaign bore fruit in May this year when the Government, through the Health Minister Lord Warner, announced that patients will be given the right to report suspected ADRs, without the intervention of a health professional, to the Medicines and Healthcare products Regulatory Agency (MHRA). ${ }^{6}$ This is the first time within the UK that patients will have this right. Already patients are able to report their own ADRs to NHS Direct, but the final decision as to whether a yellow card is completed (i.e. the ADR is reported to the regulatory authorities) depends on the NHS Direct nurse, not the patient. The details of how patients will report suspected ADRs are not yet clear; pilot schemes will be run to determine the best system. A logical step forward would be to initiate a regional pilot of direct patient reporting; this has already proved a successful way to evaluate different surveillance schemes for paediatric ADRs. ${ }^{7}$

Many countries already accept direct reporting of ADRs by patients ${ }^{8}$ but no detailed national analysis has yet been conducted on the value of this innovation. Several studies do point to benefits. A Dutch investigation compared the reporting of ADRs to paroxetine by patients and health professionals. ${ }^{9}$ The authors identified nine new ADRs which were recorded by both patients and health professionals, and in each instance the ADR was reported earlier by the patients (mean difference in lag 273 days). A Scottish group looking at treatment with antidepressants, anticonvulsants and analgesics found that patients did not invariably tell their general practitioner about symptoms they suspected to be ADRs; moreover, general practitioners did not record all the symptoms that the patient had mentioned as possibly caused by an ADR. ${ }^{10}$

If the purpose of ADR surveillance is to detect new ADRs these findings suggest that patient reporting will be of benefit, but further work is required before a national patient ADR reporting scheme is introduced. We also need to consider paediatrics, where the reporter of a suspected ADR would probably be a parent. There have been no formal investigations of such reporting, but in one prospective study of midazolam withdrawal in critically ill children it was the parents who detected abnormal behaviour in two of the young patients. ${ }^{11}$

Medawar and Herxheimer will not see the UK Government's announcement as a complete triumph. In a paper last year they argued that the MHRA is an unsuitable body to exercise pharmacovigilance because, as the organization that licenses medicines, it has a conflict of interest. ${ }^{5}$ This is an important point, and to date neither the MHRA nor the Government has fully answered it. Nor are they the only commentators to express concern about the close links between the MHRA and the pharmaceutical industry, among them being Richard Brook, chief executive of the mental health charity Mind. ${ }^{6}$ Clearly there is much to be said for separation of licensing from pharmacovigilance, but the direct reporting of ADRs by patients must not await this reform; what we need now are some pilot schemes to see how it can best be done.

\section{Imti Choonara}

Academic Division of Child Health,

University of Nottingham,

Derbyshire Children's Hospital,

Derby DE22 3DT, UK

E-mail: imti.choonara@nottingham.ac.uk 


\section{REFERENCES}

1 Choonara I, Rieder MJ. Drug toxicity and adverse drug reactions in children - a brief historical review. Paediatr Perinatal Drug Ther 2002;5:12-18

2 Impicciatore P, Choonara I, Clarkson A, et al. Incidence of adverse drug reactions in paediatric in/out-patients: a systematic review and meta-analysis of prospective studies. Br J Clin Pharmacol 2001;52: $77-83$

3 Lazarou J, Pomeranz B, Corey PN. Incidence of adverse drug reactions in hospitalized patients: a meta-analysis of prospective studies. JAMA 1998;279:1200-5

4 Clarkson A, Choonara I. Surveillance for fatal suspected adverse drug reactions in the UK. Arch Dis Child 2002;87:462-7

5 Medawar C, Herxheimer A. A comparison of adverse drug reaction reports from professionals and users, relating to risk of dependence and suicidal behaviour with paroxetine. Int $J$ Risk Safety Med 2003;16:5-19
6 Boseley S. Patients get the right to report drug side-effects. Guardian, 5 May 2004:7

7 Clarkson A, Conroy S, Burroughs K, Choonara I. Surveillance for adverse drug reactions in children: a paediatric regional monitoring centre. Paediatr Perinat Drug Ther (in press)

8 van Grootheest K, de Graaf L, de Jong van den Berg LTW. Consumer adverse drug reporting: a new step in pharmacovigilance? Drug Safety 2003;26:211-17

9 Egberts TCG, Smulders M, de Koning FHP, et al. Can adverse drug reactions be detected earlier? A comparison of reports by patients and professionals. BMJ 1996;313:530-1

10 Jarernsiripornkul N, Krska J, Capps PAG, et al. Patient reporting of potential adverse drug reactions: a methodological study. Br $J$ Clin Pharmacol 2002;53:318-25

11 Hughes J, Gill A, Leach HJ, et al. A prospective study of the adverse effects of midazolam on withdrawal in critically ill children. Acta Paediatr 1994;83:1194-9

\section{Case II}

Communicated by Mr. Archdeacon, Surgeon at St. Neots, in a letter dated Sept. 19, 1747.

One Gibbs, the wife of a coal-porter in this place, had long complained of violent pain in the bladder, with other fymptoms of a ftone but met with little compaffion, becaufe fufpected of idlenefs, rather than of having any real diforder. She afterwards proved with child, and endured great torment all the time of geftation, till fhe fell in labour, when the midwife being called, was furprized to find a hard body prefenting before the head of the child. She did not know how to act upon this occafion, but the patient's circumfstances not permitting her to employ a male practitioner, patience was the only remedy fhe had to fupport her through a long and painful labour. At laft the midwife felt fomething come away, and upon examination, found it was a fone of the fhape and fize of a goofe's gizzard, weighing five or fix ounces, which fhe afterwards gave to doctor Waller of Cambridge. The child followed immediately after it was difcharged, and proved to be a boy, who is now a Blackfmith in London, about twenty-eight or thirty years of age. The woman recovered very well, but was troubled with an involuntary emiffion of urine; fhe afterwards bore a daughter and lived feveral years, until fhe was fhot by accident, at a gentleman's houfe in this town.

From: A Collection of Cases and Observations in Midwifery. By William Smellie, MD, to illustrate His former Treatise, or First Volume on that Subject. London: Printed for D Wilson and T Durham, at Plato's Head, in the Strand, MDCCLIV 